\title{
Proposing University Students Learning Approach -Learning and Playing via Facebook
}

\author{
Ming-Kuei Yeh \\ Dept. of Information Management \\ National Taipei U. Business \\ Taipei City, Republic of China \\ e-mail: c8880@ms21.hinet.net, \\ jamesyeh@ntub.edu.tw
}

\author{
Sarah Hsueh-Jui Liu \\ Department of Applied English \\ Kainan University \\ Taoyuan City, Republic of China \\ e-mail: sarah.hjliu@gmail.com, \\ sarahliu@mail.knu.edu.tw
}

\author{
Zih-Ping Ho \\ Business Intelligence Research Center \\ National Taipei U. Business \\ Taipei City, Republic of China \\ e-mail: tp.her@msa.hinet.net, \\ zihping@ntub.edu.tw
}

\begin{abstract}
Game enhanced learning (GEL) or computer aids education (CAE) presupposes that game-like applications and computer-based tools enable to improve learners' cognitive and social skills. However, there is a limited amount of relevant literature and empirical studies available to provide a better understanding of how the fuzzy mathematical model is applied in an English-as-a-foreign-language (EFL) learning context. This research is intended to propose a decision-making model on the university EFL students' approach to learning through playing games on Facebook. This study administered an online questionnaire to the university students, and then mined their opinions, in an attempt to build a possible learning approach and analyzing model. The issue of whether CAE combining games motivates university students to learn is explored by employing the fuzzy decision-making model which was applied within this case study. The results indicated a positive relationship between learning and playing games via Facebook as university students playing games on Facebook would enhance learning the subject of English, especially in enhancing learning motivation. This research suggests that it is necessary to apply this fuzzy model in other courses in order to make comparisons. It also suggests that teachers should design simple games for their lessons to enhance their students' learning motivation.
\end{abstract}

Keywords- computer aid education; CAE; fuzzy decisionmaking model; dynamic programming; Facebook and internet game; English-as-a-foreign language; flipped education

\section{INTRODUCTION}

In modern education, the underlying aspects of information retrieval, computer/technological applications, and learning motivation are highly emphasized in order to enhance students' learning experiences. In particular, computer aids education (CAE) via the Internet or game activities in virtual reality has been prevalent in the last two decades or so. A number of well-established applications of CAE, such as Second Life and Facebook, allow students to facilitate genuine communication with others. In language education, those applications are deemed to help increase students' motivation and interest in learning the target language.

The purpose of this study focuses on the university students' approach to learning through playing games, whereby students employed Facebook to facilitate effective learning the given subject via playing games. From learning and gameplay elements, it may help teachers to integrate their teaching materials with games into the classrooms.

\section{LITERATURE REVIEW}

Research and relevant theories in CAE via the Internet or online games for learning some subjects or languages has been scarcely found for the past years. Despite this, the relation between learning and gameplay has been found positive as GEL potentially fosters learners' skills, such as problem-solving and decision-making skills and creativity [1] and communicative skills in the target language [2]. As such, Lombardi [3] points out that humor in video games may cultivate language learners' intrinsic motivation as the humor has a neurobiological basis that has great impact on language learning, such as feeling fun relating to the neurotransmitter dopamine in the mesolimbic region of the brain.

In a language learning context, Ashraf et al. [4] examined the impact of online games on vocabulary learning by Iranian EFL students. Their findings suggest that online computer games tended to improve students' vocabulary knowledge in the target language as the experimental group outperformed the control group in the vocabulary posttest whereby the former utilized online games whilst the latter did not. Those findings indicate that online games can effectively help students acquire new words by sharing information with others, competing or collaborating with their peers to complete a given task. Besides, there is possibility of using linearization methods to solve fuzzy objective problems, as Huang [5] proposed a piecewise linearization method to express the linear membership function.

In Sabatino's [6] writing, online games such as Mafia Wars on Facebook engage students in authentic situations where they are required to develop a series of plans and actions to solve problems during the writing process.

It is worth noting that Facebook as the most popular social network among students [7] should be used within or outside the classroom in order to increase students' engagement and participation. Milošević et al. [7] investigated whether their participants had positive attitude towards using Facebook as a virtual classroom. In that study, SEM methodology (Structural Equation Modeling) was adopted to measure a number of variables (e.g., usefulness and group identity). As a result, their participants frequently used Facebook to maintain social relations with their friends, 
such as making new friends and keeping in touch with friends. In addition, Tsai et al. [8] developed a game-based formative assessment for energy education to improve students' participation in an online course in which students undertook the assessment as if they played a game. Those research findings indicated the gaming modes of online games (single- and multi-player) were unlikely to affect learning effectiveness and participation perceptions, whereas feedback types (with and without immediate elaborated feedback) significantly affected learning effectiveness. The results reveal that the game-based tool facilitated the enhancement of energy knowledge attainment and participants' enjoyment in this given environment

By adopting self-determination theory (SDT) to measure some variables (e.g., competence and autonomy), Akbari et al. [9] aimed to determine the differences in English learning between use of a Facebook page and a face-to-face mode. The results suggest that a significant difference existed between the two groups in terms of the learning outcomes and the SDT variables. That is, those who were in the Facebook group felt more autonomous, competent and related than those who were in the face-to-face group

Alias et al. [10] investigated the potential of video games in teaching the Malayan language for foreign students in higher education. The primary aim of that study was to consolidate the components of the experts' opinions about types of video games, predicted year of appearance, and suitability of types of video games. Their results supported those found in previous studies that video games enabled to develop learners' vocabulary knowledge in the target language. In medical education, Gauthier et al. [11] pointed out that game activities were likely to develop problemsolving strategies that might result in better learning outcomes and increase students' engagement in study. Thus far, although some literature and research studies have discussed and investigated the relationship between language learning and online games, there are still a few studies attempting to propose a new mathematical model, especially in the fuzzy math model on university students' approach to learning through playing games on Facebook.

\section{PROBLEM FORMULATION}

This research adopted a fuzzy decision making model [12], with a new application into computer aid education, finding the minimal penalty of a distance between university student choices and training samples. In this fuzzy model [12], previous research helps this study constructs a more precise problem formulation. In this study, $N$ denotes set of university student choices whilst $n$ denotes number of university student choices. Let $i, j$ denote choice number, $i \neq j$. Let $t$ denote the trials, $t=1,2, \ldots, n$, also an information process loop. Let $y_{t}$ denote a computer interface choice function $\left(y_{t}=1,2, \ldots\right.$, or $\left.n\right)$, at $t^{\text {th }}$ information process loop. Let $\boldsymbol{C}$ denote a penalty cost, a distance between historical chnire and a new student choice adding to this evaluation. Let $P_{t}$ denote the vector of input choices, a list of binary variable, at $t^{\text {th }}$ information process loop. Let $w_{k}$ denote cumulative weight of level $k$ of questionnaire, increasing or descending degree real number, is also a variable, $k=1,2, \ldots, 5$.

This model is shown as follows:

$N$ : set of university student choices

$n$ : number of university student choices, $n \in N$

$i, j$ : choice number, $i \neq j$

$t$ : the trials, $t=1,2, \ldots, n$

$y_{t}:$ a computer interface choice function $\left(y_{t}=1,2, \ldots\right.$, or $\left.n\right)$, at $t^{\text {th }}$ information process loop

$a_{t}$ : is an answer of different student opinions, at $t^{\text {th }}$ information process loop

$\boldsymbol{C}$ : a penalty cost, a distance between historical choice and new student choice adding to this evaluation

$c=\sum_{t=1}^{n}\left(y_{t}-a_{t}\right)^{2}$

Besides,

$P_{t}$ : is the vector of input choices, a list of binary variable, at $t^{\text {th }}$ information process loop, belongs to decision variable

$P_{t}=\left[p_{1}, p_{2}, \ldots, p_{n}\right]_{t}$, and $\sum_{j=1}^{n} p_{j}=1 \quad \forall t$

$w_{k}$ : cumulative weight of level $k$ of questionnaire, increasing or descending degree real number, is also a variable, $k=1,2, \ldots, 5$, belongs to decision variable

$\gamma=\frac{\sum_{k \in N} \sum_{j=1}^{n} w_{k} p_{j}}{\sum_{k \in N} \max \left\{w_{k}\right\}}$

$x_{t}=\left\{\begin{array}{rr}1, & 0 \leq \gamma<0.25 \\ 2, & 0.25 \leq \gamma<0.5 \\ 3, & 0.5 \leq \gamma<0.75 \\ 4, & 0.75 \leq \gamma<1 \\ 5, & \gamma=1\end{array}\right.$ 
$y_{t}=x_{t} P_{t}$

$y_{t}$ would be a choice

The MIP model is to minimize the penalty, the objective is as follows:

\section{Min $C$}

s.t.

$$
\begin{aligned}
& \sum_{j=1}^{n} p_{j}=1 \\
& p_{j} \in\{0,1\}
\end{aligned}
$$$$
\forall \quad t
$$

The objective (1) is to find a minimal penalty. In Eq. (2), in a $t^{\text {th }}$ trials, there is only one choice that would be selected. Eq. (3) declares artificial binary decision variable constraints.

Through this fuzzy decision making model, a different student choice is regarded as a different training sample. A five Likert scale, $k=1,2, \ldots, 5$, represents ranging from "strongly disagree" to "strongly agree," which would also be fuzzy processed, forming a new fuzzy decision model regarding this classroom students' opinions. The computer process flowchart also showed in Figure 1.

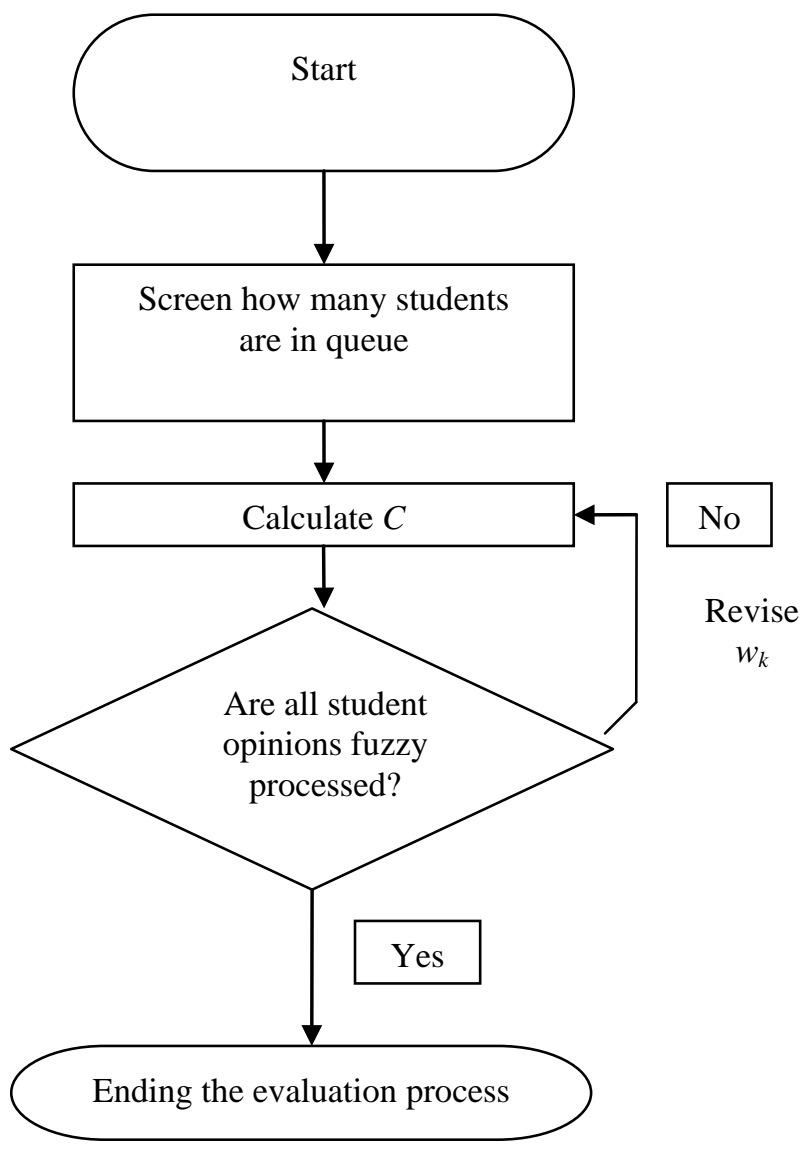

Figure 1. A flow chart of the proposed approach

\section{CASE Demostration AND CACUlation}

In recent global research hot topics, mobile computing is a trend and on-line computing and analyzing becomes a new industrial standard. Therefore, this study followed the proposed approach for solving applied mathematic research topics. In this section, the algorithm was coded in PHP computer language with Celeron (R) Dual-Core CPU at 2.10 $\mathrm{GHz}$ and 2GB of RAM memory. This MIP model is a strong NP-hard problem [13]. Since the proposed model is a new problem in the computer aid education field, no published solution method is available for comparison. Thus, this research conducted a pioneer case study.

The flow chart of the proposed approach (See Fig.1) stated that in the beginning, the software screen shows how many students are in the queue. After that, based on the model in section III, this is used to calculate $C$. The detail fuzzy decision process (how to put data into the fuzzy model), readers can refer [12]. If all students' online opinions are fuzzy processed, then end the evaluation process; otherwise, the flow goes back to the previous step and revises $W_{k}$. The dynamic decision making model can exactly solve this type of mathematical formula. 
The research was conducted in an English teaching class as a case study. There were more than 200 university students recruited. To reduce the calculation complexity, we only randomly selected $10 \%$ of data, 20 students, for further analysis. Due to this study as a pioneer one, the calculation process had to manually check each participant's data, and review the accuracy of the program's automatic process.

The on-line questionnaire survey was modified in accordance with Davis [14] and with Holden and Rada [15]. Each questionnaire was rated by a 5-point Likert scale, allowing the individuals to rate each statement from 1 to 5 , ranging from "strongly disagree" to "strongly agree." This study focused on the learning and playing part rather than the entire version of the questionnaire. Other Facebook interesting issues were not discussed in this study due to the research purpose of this case study.

The results of this study (See Fig. 2) showed the variation of weight $k$ in each iteration, where the fuzzy weight showed an increasing trend and finally student choice with over $60 \%$ scores. It meant that gameplay on Facebook would enhance subjects' learning in English. Figure 3 showed the variation of objective $C$. The dotted line represented prediction error in each iteration based on the formula calculation. The solid line was objective $C$ value. Both figures 1 and 2 showed that the fuzzy decision making model precisely caught the trend and the model prediction function was good.

The teaching materials should encourage university students learning subject through playing games on Facebook to enhance their learning motivation.

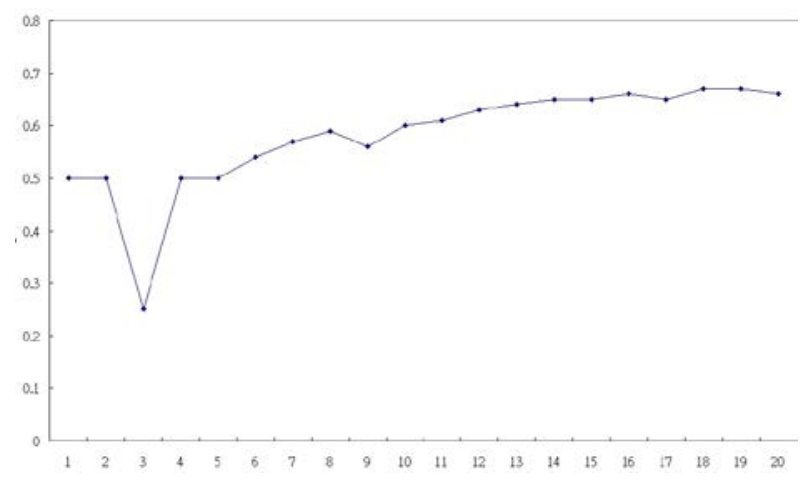

Figure 2. An increasing trend of students

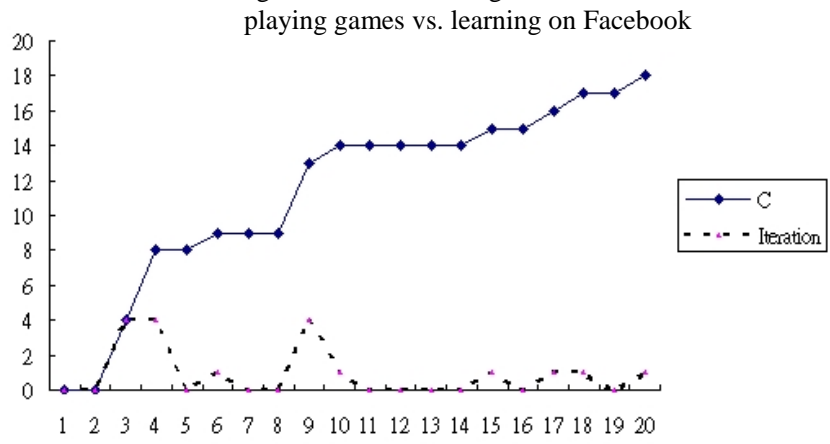

Figure 3. A variation of objective $C$

\section{CONCLUSIONS}

CAE via internet or game has been a popular topic in the last two decades. This research explored whether CAE combining games motivates university students to learn. Through this case study, the answer is positive. This pioneer study aimed to propose a university students' approach to learning through playing games of Facebook, which placed an emphasis on the aspects of learning and gameplay. The fuzzy decision-making model was applied into the CAE field, and students' choices were regarded as different training samples in this case study. With the case demonstration and calculation, the results showed that university students playing games on Facebook would enhance learning the given subject as well as enhance their learning motivation.

Future research is suggested that applying this fuzzy decision-making model into other courses is needed to compare the data of varied courses to those of English courses. It further suggests that teachers should design easier games into their lessons for enhancing their motives to achieve their learning goals.

\section{ACKNOWLEDGMENT}

The work is financially supported by the Ministry of Science and Technology of Republic of China. The grand numbers are MOST 103-2511-S-424-004 and 103-2221-E141-005. This research is also partially funded by the project of ICT Innovation and Cultivating Talents Promotion Grand, Ministry of Education of R.O.C., the grand number of NTUB is $104 \mathrm{G} 060-2$.

\section{REFERENCES}

[1] S. Freitas, K. Kiili, M. Ney, M. Ott, M. Popescu, M. Romero, and I. Stanescu, "GEL: Exploring game enhanced learning," Procedia Compu. Sci., vol. 15, 2012, pp. 289-292.

[2] W. L. Johnson, "Serious use of a serious game for language learning," Int. J. Artificial Intelli. in Edu., vol. 20, 2010, pp. 175-195.

[3] I. Lombardi, "Not-so-serious games for language learning," Proc. Compu. Sci., vol. 15, 2012, pp. 148-158.

[4] H. Ashraf, F. G. Motlagh , and M. Salami, "The impact of online games on learning English vocabulary by Iranian (Low-intermediate) EFL learners,” Proc. - Soc. and Beha. Sci., vol. 98, 2014, pp. 286-291.

[5] C. H. Huang, "An effective method for a fuzzy multiobjective program with quasiconcave membership functions and fuzzy coefficients," Int. J. Fuzzy Sys., vol. 16, 2014, pp. 256-264.

[6] L. Sabatino, "Improving writing literacies through digital gaming literacies: Facebook gaming in the composition classroom," Compu. and Composition, vol. 32, 2014, pp. 41-53.

[7] I. Milošević, D. Živković, S. Arsić , and D. Manasijević, "Facebook as virtual classroom - Social networking in learning and teaching among Serbian students," Telematics and Informatics, vol. 32, 2015, pp. 576585.

[8] F. H. Tsai, C. C. Tsai , and K. Y. Lin, "The evaluation of different gaming modes and feedback types on game-based formative assessment in an online learning environment,” Compu. \& Edu., vol. 81, 2015, pp. 259-269.

[9] E. Akbari, A. Pilot, and P. R.J. Simons, "Autonomy, competence, and relatedness in foreign language learning through Facebook," Compu. in Hum. Beha., vol. 48, 2015, pp. 126-134. 
[10] N. Alias, F. Rosman, M. N. A. Rahman , and D. Dewitt, "The potential of video game in Malay language learning for foreign students in a public higher education,” Pro. - Soc. \& Beha. Sci., vol. 176, 2015, pp. 1020-1027.

[11] A. Gauthier, M. Corrin , and J. Jenkinson, "Exploring the influence of game design on learning and voluntary use in an online vascular anatomy study aid,” Compu. \& Edu., vol. 87, 2016, pp. 24-34.

[12] Z. C. Hou, Z. P. Ho , and M. K. Yeh, "Fuzzy decision making of recommendation retail system," 14th International Business Administration Conference and Academic Forum on National Taipei University of Business, National Taipei U. Business Press, May 15th 2015, No. A2\&P.39, pp.1-7.
[13] K. H. Rosen, “Discrete mathematics and its applications,” McGraw Hill press, 2006.

[14] F. D. Davis, "Perceived usefulness, perceived ease of use, and user acceptance of information technology,” MIS Quar., vol. 13, 1989, pp. 319-340.

[15] H. Holden and R. Rada, "Understanding the influence of perceived usability and technology self-efficacy on teachers technology acceptance,” J. Res. on Tech. in Edu., vol. 43, 2011, pp. 343-367. 